Original Article

\title{
Liver Function in Non - Pregnant Hyperthyroid Women: A Hospital Based Cross Sectional Study from Northern Pakistan
}

Jasmine Shah, Mohammad Yousaf, Muhammad Rasul Jan

\section{ABSTRACT}

INTRODUCTION: Functions of almost all body cells and organs are influenced by thyroid hormones; therefore malfunction of thyroid gland may cause serious clinical problems affecting major organs like liver and kidney.

OBJECTIVE: The objective of the study was to evaluate the effect of hyperthyroidism on liver function. METHODOLOGY: This hospital- based cross sectional study was conducted on 163 non-pregnant women in the age group of 18-75 years to evaluate the effects of hyperthyroidism on the biochemical markers of liver function. Serum $\mathrm{T}_{3}, \mathrm{~T}_{4}, \mathrm{TSH}$ and liver function tests were carried out using standard methods and kits.

RESULTS: No significance differences were found in the ALT (AlanineTransaminase) and AST (Aspartate Transaminase) level in all the three groups. ALT level was found to be $33.14 \pm 2.98$ in $\mathrm{OH}$ (Overtly hyperthyroid), $29.50 \pm 1.69$ in $\mathrm{SH}$ (Sub clinically hyperthyroid) group as compared to $29.69 \pm 3.28$ IU/L in N (Normal) group. AST(Aspartate Transaminase) level was $33.70 \pm 5.12$ I U/L in N group, $30.68 \pm 2.7$ in $\mathrm{OH}$ group and $30.38 \pm 2.6 \mathrm{I} \mathrm{U/L}$ in $\mathrm{SH}$ group. Avery significant positive correlation was found between AST and TSH in the $N$ group $(p=0.002)$ and $B M I$ and $T_{3}$ in $N$ and $O H$ group respectively $(p=0.01)$. No significant correlation was found between liver enzymes and thyroid profile markers in any of the study groups.

CONCLUSION: The study shows that hyperthyroidism has no severe effects on liver function.

KEY WORDS: Hyperthyroidism, Liver enzymes, Alanine Transaminase, Hormone, Non-Pregnant Women.

This article may be cited as: Shah J, Yousaf M, Jan MR. Liver Function in Non - Pregnant Hyperthyroid Women: A Hospital Based Cross Sectional Study from Northern Pakistan. J Liaquat Uni Med Health Sci. 2017;16(04):194-99. doi: 10.22442/jlumhs.171640532

\section{INTRODUCTION}

Thyroid hormones are important endocrine hormones necessary for the growth, development and normal functions of all tissues and organs with its major effects on liver ${ }^{1}$. Its bio synthesis and secretion is regulated by a negative feedback mechanism involving the thyroid gland and pituitary hypothalamus axis $^{2}$.

These hormones regulate the Basal Metabolic Rate (BMR) of Hepatocytes, and hence play a vital role in the normal liver functions. The liver regulates the endocrine function of the thyroid gland and also metabolize its hormones ${ }^{3}$. Normal functioning of thyroid gland and serum levels of the thyroid hormones is necessary for the normal function of liver and bilirubin metabolism ${ }^{4}$. Thyroid dysfunction may disturb liver functions and vice-versa ${ }^{3}$. Abnormal biochemical liver function tests are usually observed in overt thyroid dysfunctions and in severe forms with histologically evident hepatocellular damage ${ }^{5}$. In severe cases of thyroid failure the rate of bile flow and biliary flow of bilirubin and bile salts are highly reduced ${ }^{6}$. Liver injury in hyperthyroidism may take any of the two forms 1) hepatitis and 2) cholestatic. In hepatitis injury no other biochemical features of liver disease are evident except rise of serum level of Aspartate Aminotransferase (AST) and Alanine Aminotransferase (ALT) in $27 \%$ and $37 \%$ of patientsrespectively ${ }^{7}$. In few patients suffering from thyrotoxicosis, liver failure is also reported ${ }^{8}$. In cholestatic injury, level of serum alkaline phosphatase was found to be elevated in $64 \%$ of patients suffering from Overt Hyperthyroidism $(\mathrm{OH})^{9}$. There are also reports that untreated hyperthyroidism in some patients may cause focal necrosis with fatty change to cirrhosis ${ }^{10}$.

Thyroidal dysfunctions are more prevalent in females and its adverse effects in pregnant females are well established. Hyperthyroidism is 10 times more common in women than in men ${ }^{11}$. It has been found to occur in around $2.5 \%$ of normal pregnancies ${ }^{12}$. According to a WHO report on the nutritional value of vitamins and minerals, the prevalence of goiter in Pregnant Women (PW) is $22.2 \%$ while in Nonpregnant Women (NPW) is $20.9 \%$ respectively.

The data about the prevalence and ill effects of hyperthyroidism on liver function in Non-pregnant Women (NPW) is limited especially in south Asia in 
general and Pakistan in particular.

\section{Objective}

The purpose of this present cross-sectional study was to study the effects of thyroid hyper function on the biochemical markers of liver functions in Non-pregnant Women (NPW) of Khyber Pakhtun Khwa in Northern Pakistan.

\section{METHODOLOGY}

This cross sectional study was carried out between 01 March 2014 to 31 March 2015 in Khyber Teaching Hospital (KTH), a tertiary care hospital in Khyber Pakhtun Khwa (KPK) province of Northern Pakistan. The study was approved by the ethical committee of the Khyber Teaching Hospital (KTH), through its letter no $21876 / \mathrm{KTH} / \mathrm{P} . \mathrm{S}$. The total no of patients visiting various outpatient depts. were 539968. Out of these 281,311 were females and 258,657 were male. The total referral cases form this department for thyroid screenings were 15667.3010 were found to be newly diagnosed cases of thyroidal dysfunctions. 2303 were females and 707 were males. The ratio of female and male was 3.26:1. Among female patients, 605 were below 18 years, 442 were pregnant and 1147 were sufferings from co-morbidities affecting kidney, liver, heart or diabetes leaving behind 109 non pregnant patients that comprise the study group. Normal $(\mathrm{N})$ or control group consisting of 54 non pregnant women were recruited from the local area in Peshawar city. Informed consent was sought from each patient personally or through their attendant. The data regarding age; BMI, medical history etc was collected from the patients through a well-designed data entry form using purposive sampling method. All human dignity was respected in accordance with international norms involving human as an experimental objects. 5 $\mathrm{ml}$ of fasting venous blood sample was collected from each patient. Serum was divided into two parts, one part was used for thyroid function tests by Elisa techniques and the other was immediately analyzed for biochemical tests of ALT and AST using Standard protocols.

\section{Biochemical analysis of Thyroid markers}

Thyroid biomarkers (Serum TSH, $\mathrm{T}_{4}$ and $\mathrm{T}_{3}$ ) were evaluated using ELISA kits (Biocheck, Inc. catalog Number: BC-1001, BC-1007 and BC-1005 respectively) on Dia 710 micro plate reader (Made in Australia) using Competitive ELISA and Sandwich ELISA methods respectively ${ }^{13-15}$. The normal reference values for TSH, T4 and T3were 0.4- 6.0 $\mu$ $\mathrm{IU} / \mathrm{ml}, 4.8-12.0 \mu \mathrm{g} / \mathrm{dl}$, and $0.6-1.85 \mathrm{ng} / \mathrm{ml}$ respectively.

\section{Biochemical analysis of liver markers}

Serum ALT and AST were measured according to IFCC standard methods on chemistry autoanalyser
(Erbamannhein chemistry autoanalyser, Germany) using standard Erba kits \& protocols.

The normal range for ALT\& AST was 5-45 IU/L and 5-45 IU/L respectively.

\section{Statistical analysis of the data}

The data of the study group was statistically analyzed on SPSS for windows 21.0 software (SPSS Inc. Chicago, IL, USA) and Microsoft Excel. The values were reported as Mean \pm Standard Error (SE). Multiple linear regression \& Pearson's correlation analysis for the required parameters was also done to determine the kind of association between these parameters. A two-tailed $p$ value $<0.05$ was considered statistically significant.

\section{RESULTS}

\section{Baseline characteristic of the study group}

The study group and the control group were age matched 163 Non- pregnant women (NPW) as shown in table 1 . The mean age of patients in the control group $(\mathrm{N})$ was $42.15 \pm 1.86$ years, $49.74 \pm 1.62$ years for Overtly Hyperthyroid $(\mathrm{OH})$ and $48.94 \pm 1.87$ years for the Sub clinically Hyperthyroid $(\mathrm{SH})$. The control group was with 54 normal non pregnant women, of which $61.11 \%$ (33) were Menopausal (M, age below 45 years), $18.52 \%$ (10) were Early Post-Menopausal (EPM, age $45-50$ years) and $20.37 \%$ (11) were Late Post-Menopausal (LPM, age above 50 years). Similarly the percentage of M, EPM and LPM in the $\mathrm{OH}(58)$ and $\mathrm{SH}(51)$ were $34.48 \%(20), 27.58 \%$ (16), $37.93 \%$ ( 22) and $43.14 \%(22), 07.84 \%(04), 49.07 \%$ (25) respectively.

Comparison of the biochemical markers of thyroid function and liver function of the study group. The mean values of thyroid hormones and biochemical markers of liver function are presented in table 1 . The mean serum level of TSH was found to be lowest in $\mathrm{OH}$ group $(0.17 \pm 0.01 \mu \mathrm{lU} / \mathrm{ml})$ and highest in the $\mathrm{N}$ group $(2.38 \pm 0.49 \mu \mathrm{lU} / \mathrm{ml})$. Serum T3 level was highest in $\mathrm{OH}$ group $(2.37 \pm 0.01 \mathrm{ng} / \mathrm{ml})$ and lowest in SH group $(1.64 \pm 0.04 \mathrm{ng} / \mathrm{ml})$. Highest serum T4 level was found for $\mathrm{OH}$ group $(12.07 \pm 0.46 \mu \mathrm{g} / \mathrm{dl})$ and lowest in SH group $(8.16 \pm 0.24) \mu \mathrm{g} / \mathrm{dl})$. The mean ALT level was highest in $\mathrm{OH}$ group $(33.14 \pm 2.98 \mathrm{IU} / \mathrm{L})$ and lowest in the SH group (29.50 $\pm 1.69 \mathrm{IU} / \mathrm{L})$. Mean AST was found highest in N group (33.70 $\pm 5.12 \mathrm{IU} / \mathrm{L}))$ and lowest in $\mathrm{SH}$ group $(30.38 \pm 2.60 \mathrm{IU} / \mathrm{L})$.

Multiple linear regression analysis of thyroid profile markers and liver markers

Regression analysis is a statistical procedure of determining the kind of relationship between variables. It defines the difference of the dependent variable around the regression function. Results of multiple linear regression analysis between the thyroid 
profile markers (independent variable) and liver markers (dependent variable) for the three study groups are shown in table II-IV. Both ALT and AST are positively related with $\mathrm{TSH}$ in all the study groups. ALT show positive relation with $\mathrm{T}_{3}$ in $\mathrm{N}$ and $\mathrm{OH}$ group and negative in $\mathrm{SH}$ group. It also shows negative relation with $\mathrm{T}_{4}$ in $\mathrm{N}$ group and positive in $\mathrm{OH}$ and $\mathrm{SH}$ group. AST was positively related with $\mathrm{T}_{3}$ in $\mathrm{N}$ group and negatively related in $\mathrm{OH}$ and $\mathrm{SH}$ group. It show negative relation with $\mathrm{T}_{4}$ in $\mathrm{N}$ group and positive in $\mathrm{OH}$ and $\mathrm{SH}$ group.

\section{Correlation analysis}

Correlation analysis is a statistical method for the verification of a relationship among two variables and is expressed in term of coefficient of correlation( $r$ ). Its values are -1 to 0 to +1 . A positive relation means a direct relation and negative mean an inverse relation ${ }^{18}$. The results of correlation analysis are presented in table V. ALT was found to be positively correlated with TSH in the entire study group. With $T_{3}$ and $T_{4}$ it showed negative correlation in Group and positive correlation in $\mathrm{OH}$ and $\mathrm{SH}$ group. All these correlations were found to be non-significant. Avery significant positive correlation was found between AST and TSH in the $\mathrm{N}$ group ( $p=0.002$ ). AST was non- significantly negatively correlated with $\mathrm{TSH}$ in the $\mathrm{OH}$ and positive within SH group. AST was positively correlated in nonsignificant way with $\mathrm{T}_{3}$ in $\mathrm{N}$, and negatively in $\mathrm{OH}$ and $\mathrm{SH}$ group. Similarly AST was negatively correlated with $\mathrm{T}_{4}$ in $\mathrm{N}$ and $\mathrm{SH}$ group positively correlated with $\mathrm{OH}$ group. BMI was found to be very significantly correlated with $\mathrm{T}_{4}$ in $\mathrm{N}$ and $\mathrm{OH}$ group $(\mathrm{p}=0.01)$.

TABLE I: FREQUENCY DISTRIBUTION OF MENOPAUSAL STATUS OF THE STUDY GROUPS

\begin{tabular}{|c|c|c|c|c|c|}
\hline Group ID & Mean age (Years) & $\% \mathbf{M}(\mathbf{n})$ & $\%$ EPM $(\mathbf{n})$ & $\%$ LPM $(\mathbf{n})$ & Total \\
\hline $\mathbf{N}$ & $42.15 \pm 1.86$ & $61.11(33)$ & $18.52(10)$ & $20.37(11)$ & 54 \\
\hline OH & $49.74 \pm 1.62$ & $34.48(20)$ & $27.58(16)$ & $37.93(22)$ & 58 \\
\hline SH & $48.94 \pm 1.87$ & $43.14(22)$ & $07.84(04)$ & $49.07(25)$ & 51 \\
\hline
\end{tabular}

N: Normal, OH: Overtly hyperthyroid, SH: Sub clinically hyperthyroid, M: Menopausal, EPM: Early Postmenopausal, LPM: Late Postmenopausal.

TABLE II:

THYROID PROFILE AND LIVER FUNCTION BIOCHEMICAL MARKERS IN NON-PREGNANT WOMEN

\begin{tabular}{|c|c|r|r|r|r|r|}
\hline \multirow{2}{*}{ Group ID } & \multirow{2}{*}{ Freq. (n) } & \multicolumn{3}{|c|}{ Thyroid profile markers } & \multicolumn{1}{c|}{ Liver marker } \\
\cline { 3 - 7 } & & TSH & \multicolumn{1}{c|}{$\mathbf{T}_{\mathbf{3}}$} & \multicolumn{1}{c|}{$\mathbf{T}_{\mathbf{4}}$} & \multicolumn{1}{c|}{ ALT } & \multicolumn{1}{c|}{ AST } \\
\hline $\mathrm{N}$ & 54 & $2.38 \pm 0.49$ & $1.68 \pm 0.05$ & $8.50 \pm 1.59$ & $29.69 \pm 3.28$ & $33.70 \pm 5.12$ \\
\hline $\mathrm{OH}$ & 58 & $0.17 \pm 0.01$ & $2.37 \pm 0.01$ & $12.07 \pm 0.46$ & $33.14 \pm 2.98$ & $30.68 \pm 2.7$ \\
\hline $\mathrm{SH}$ & 51 & $0.18 \pm 0.01$ & $1.64 \pm 0.04$ & $8.16 \pm 0.24$ & $29.50 \pm 1.69$ & $30.38 \pm 2.60$ \\
\hline $\begin{array}{l}\text { N: Normal, OH: Overtly hyperthyroid, SH: Sub clinically hyperthyroid, TSH: Thyroid Stimulating Hormone, } \\
\text { T3: Triiodothyronine, T4:Tetraiodothyronine, ALT: Alanine Transaminase, AST: AspartateTransaminase. }\end{array}$
\end{tabular}

TABLE III: MULTIPLE LINEAR REGRESSION ANALYSIS OF THYROID PROFILE WITH LIVER MARKERS IN THE NORMAL GROUP (N)

\begin{tabular}{|c|c|c|c|c|c|}
\hline \multirow{2}{*}{\multicolumn{2}{|c|}{$\frac{\text { Model }}{\text { DV }}$}} & \multicolumn{4}{|c|}{ Unstandardized coefficients } \\
\hline & & \multicolumn{2}{|c|}{ ALT } & \multicolumn{2}{|c|}{ AST } \\
\hline \multirow{2}{*}{\multicolumn{2}{|c|}{ Constant }} & B & SE & B & SE \\
\hline & & 30.16 & 23.11 & 28.56 & 13.33 \\
\hline \multirow{3}{*}{ IV } & TSH & 4.01 & 2.55 & 4.80 & 1.47 \\
\hline & $\mathrm{T}_{3}$ & 10.43 & 9.24 & 3.97 & 5.33 \\
\hline & $\mathrm{T}_{4}$ & -3.04 & 2.08 & -1.82 & 1.20 \\
\hline
\end{tabular}

Dependent variable: DV, Independent Variable: IV, Standard Error: SE
TABLE IV: MULTIPLE LINEAR REGRESSION ANALYSIS OF THYROID PROFILE WITH LIVER MARKERS IN THE OVERTLY HYPERTHYROID GROUP (OH)

\begin{tabular}{|c|c|c|c|c|c|}
\hline \multirow{2}{*}{\multicolumn{2}{|c|}{$\frac{\text { Model }}{\text { DV }}$}} & \multicolumn{4}{|c|}{ Unstandardized coefficients } \\
\hline & & \multicolumn{2}{|c|}{ ALT } & \multicolumn{2}{|c|}{ AST } \\
\hline \multirow{2}{*}{\multicolumn{2}{|c|}{ Constant }} & B & SE & B & SE \\
\hline & & 10.18 & 15.41 & 23.10 & 13.97 \\
\hline \multirow{3}{*}{ IV } & TSH & 34.5 & 33.86 & 30.53 & 30.69 \\
\hline & $\mathrm{T}_{3}$ & 3.88 & 4.74 & -3.62 & 4.3 \\
\hline & $\mathrm{T}_{4}$ & 0.66 & 0.95 & 0.92 & 0.86 \\
\hline
\end{tabular}


TABLE V: MULTIPLE LINEAR REGRESSION ANALYSIS OF THYROID PROFILE WITH LIVER MARKERS IN THE SUB CLINICALLY HYPERTHYROID GROUP (SH)

\begin{tabular}{|c|c|r|r|r|r|}
\hline \multicolumn{2}{|c|}{ Model } & \multicolumn{3}{c|}{ Unstandardized coefficients } \\
\hline \multicolumn{2}{|c|}{ DV } & \multicolumn{2}{|c|}{ ALT } & \multicolumn{2}{c|}{ AST } \\
\hline \multirow{2}{*}{ Constant } & \multicolumn{1}{c|}{$\mathrm{B}$} & \multicolumn{1}{c|}{ SE } & \multicolumn{1}{c|}{ B } & \multicolumn{1}{c|}{ SE } \\
\cline { 3 - 7 } & 16.00 & 10.10 & 51.36 & 15.3 \\
\hline \multirow{3}{*}{ IV } & \multicolumn{1}{|c|}{$\mathrm{TSH}^{2}$} & 28.4 & 18.60 & 38.81 & 28.17 \\
\cline { 2 - 6 } & $\mathrm{T}_{3}$ & 3.55 & 6.11 & -16.16 & 9.25 \\
\cline { 2 - 6 } & $\mathrm{T}_{4}$ & 0.33 & 1.12 & -0.18 & 1.69 \\
\hline
\end{tabular}

TABLE VI: CORRELATION ANALYSIS OF LIVER MARKERS WITH TSH, T3 AND T 4 IN THE STUDY GROUPS

\begin{tabular}{|c|c|r|r|r|r|}
\hline \multirow{4}{*}{ Parameter } & \multirow{2}{*}{$\begin{array}{c}\text { Group } \\
\text { ID }\end{array}$} & \multicolumn{3}{|c|}{$\begin{array}{c}\text { Biochemical markers of } \\
\text { liver function }\end{array}$} \\
\cline { 3 - 6 } & & \multicolumn{2}{|c|}{ ALT } & \multicolumn{2}{c|}{ AST } \\
\cline { 3 - 6 } & $\mathrm{R}$ & $\mathrm{p}$ & $\mathrm{R}$ & $\mathrm{p}$ \\
\hline \multirow{3}{*}{$\mathrm{TSH}$} & $\mathrm{N}$ & 0.20 & 0.16 & $0.41^{\text {** }}$ & 0.002 \\
\cline { 2 - 6 } & $\mathrm{OH}$ & 0.09 & 0.49 & -0.64 & 0.67 \\
\cline { 2 - 6 } & $\mathrm{SH}$ & 0.06 & 0.63 & 0.13 & 0.32 \\
\hline \multirow{3}{*}{$\mathrm{T3}$} & $\mathrm{N}$ & -0.27 & 0.05 & 0.06 & 0.68 \\
\cline { 2 - 6 } & $\mathrm{OH}$ & 0.13 & 0.33 & -0.09 & 0.50 \\
\cline { 2 - 6 } & $\mathrm{SH}$ & 0.65 & 0.63 & -0.60 & 0.66 \\
\hline \multirow{3}{*}{$\mathrm{T}_{4}$} & $\mathrm{~N}$ & -0.18 & 0.18 & -0.20 & 0.15 \\
\cline { 2 - 6 } & $\mathrm{OH}$ & 0.12 & 0.36 & 0.08 & 0.56 \\
\cline { 2 - 6 } & $\mathrm{SH}$ & 0.01 & 0.94 & -0.01 & 0.92 \\
\hline
\end{tabular}

*. Correlation is significant at the 0.05 level (2-tailed).

**. Correlation is significant at the 0.01 level (2-tailed).

\section{DISCUSSION}

Hyperthyroidism causes liver dysfunctions, which are associated with the effects of thyroid hormone excess $^{5,19}$. In patients, with untreated hyperthyroidism, changes in liver biochemistry are most frequently observed ${ }^{20-22}$, but these biochemical changes are usually reversible and can be normalized after treatment with appropriate drugs.

A no of studies have reported the biochemical abnormalities of liver functions in untreated patients with thyrotoxicosis. As there is a strong associations between liver and thyroid and hence any abnormality in one may cause confusions in the biochemical tests either for liver or thyroid function tests. Thus it is important to measure thyroid profile markers (TSH, T3 \& T4) in any patient with abnormal liver function markers, to rule out coexistent possibility of thyroid dysfunctions. Biscoveanu et al examined the clinical records of 30 cases of Grave's disease and found that $11(37 \%)$ patients had abnormal results for biochemical markers of liver function tests like ALK, AST, ALT, GGT and bilirubin ${ }^{23}$.

Thyroidal dysfunction is a common health problem of endocrine gland in northern Pakistan with highest frequency in females due to unknown etiology. Its prevalence rate among general population is believed to be $5.1 \%$ with higher prevalence rate in females ${ }^{24}$.

In the present study we attempted to assess liver health inpatients with confirmed hyperthyroidism. The data presented here show the effect of biochemical markers of thyroid function on liver function in nonpregnant women in Khyber Pakhtun Khwa province of northern Pakistan. It shows the effect of change in the serum level of thyroid biochemical markers on the level of liver function markers in the study groups.

Our study group mainly consist of Non pregnant women $(n=163)$ which were the new referral cases for thyroid screening to a tertiary care hospital.

In our study no significance differences were found in the ALT and AST level in all the three groups. ALT level was found to be slightly elevated while AST level was little depressed in $\mathrm{OH}$ group as compared to $\mathrm{N}$ group. This range of liver dysfunctions is consistent with other similar studies reported in the literature, where no significant change in the level of liver enzymes was observed in hyperthyroid patients.

$Y$ Mane $A$ et al evaluated the liver functions tests of 45 confirmed hyperthyroid patients and found it normal ${ }^{25}$. This shows that hyperthyroidism has no severe effects on liver function. Therefore, the possibility of liver impairment in thyroid dysfunction is ruled out. Some researchers have reported a strong association between liver function and thyroid hormones metabolism 26-27. Thyroidal dysfunctions are also found to be associated with liver injuries with not yet fully understood mechanism ${ }^{7}$ and elevation of liver enzymes, ALT, AST and ALP. The discrepancies in our results and other reported in literature may be due to a no of factors like, racial differences, sex, age, nutritional status and genetic makeup of our study group.

The important aspects of this study is that no such study has been reported from this area of northern Pakistan where the prevalence rate of hyperthyroidism is almost $5.1 \%$ with higher prevalence rate in females than in males ${ }^{23}$.

All these findings of our study are important in understanding the intricate interactions between the thyroid gland and liver. The findings of our study 
provide a multisystem approach to treat patients with diseases affecting either thyroid or liver. This study has got a no of limitations which according to our view were unavoidable. The first and foremost is the socio cultural barriers specific to this area hindering the collection of authentic data regarding family history, medical history and social status. The other limitations of the study include financial constraint, time limitation, and small study group pertaining to non-pregnant women only in one Centre only. Lastly thyroid profile markers were measured by ELISA technique, it would have been better to be measured by Radio immunoassay which is considered superior to our procedure. Further studies are required involving lager populations for better understanding of the intricate interactions between the thyroid gland and liver.

\section{Financial disclosure}

The study was not supported by any agency in any form.

\section{Conflict of interest: None}

\section{REFERENCES}

1. Yen PM. Physiology and molecular basis of thyroid hormone action. Physiol Rev 2001; 81 (3):1097-142.

2. Chin KY, Ima Nirwana $S$, Mohame IN, Aminuddin A, Johari MH, Wan Ngah WZ. The Relationships between Thyroid Hormones and Thyroidstimulating Hormone with Lipid Profile in Euthyroid men. Int J Med Sci 2014; 11(4): 349-355. doi: 10.7150/ijms.7104

3. Arora S, Chawla R, Tayal D, Gupta VK, Sohi JS, Mallika V. Biochemical markers of liver and kidney function are influenced by thyroid function- a case -controlled follow up study in Indian hypothyroid subjects. Ind J Clin Biochem 2009; 24 (4): 370374. doi: 10.1007/s12291-009-0067-1

4. Oda E, Aizawa Y. Total bilirubin is inversely associated with metabolic syndrome but not a risk factor for metabolic syndrome in japanese men and women. Acta Diabetol 2013; 50: 417-422.

5. Khemichian S, Fong T. Hepatic Dysfunction in Hyperthyroidism. Gastroenterol Hepatol (NY) 2011; 7(5): 337-339.

6. Deetman PE, Bakker SJL, Kwakernaak AJ, Navis G, Dullaart RPF, and on behalf of the PREVEND study group. The Anti-Oxidant Bilirubin with Free Thyroxine is Modified by Insulin Resistance in Euthyroid Subjects. PLoS ONE 2014 9(3): e90886. doi:10.1371/journal.pone.0090886.

7. Kubota S, Amino N, Matsumoto $\mathrm{Y}$, et al. Serial changes in liver function tests in patients with thyrotoxicosis induced by Graves'disease and painless thyroiditis. Thyroid 2008; 18(3):283-7.

8. He K, Hu Y, Xu XH, et al. Hepatic dysfunction related to thyrotropin receptor antibody in patients with Graves' disease. Exp Clin Endocrinol Diabetes 2014; 122(06):368-372. DOI: 10.1055/s0034-1375667.

9. Ittermann $\mathrm{T}$, Haring $\mathrm{R}$, Wallaschofski $\mathrm{H}$, et al. Inverse association between serums free thyroxine levels and hepatic steatosis: Results from the Study of Health in Pomerania. Thyroid 2012; 22 (6):568-574. doi: 10.1089/thy.2011.0279.

10. de Campos Mazo DF, de Vasconcelos GB, Pereira MA, et al. Clinical spectrum and therapeutic approach to hepatocellular injury in patients with hyperthyroidism. Clin Exp Gastroenterol 2013; 6: 9-17. doi: 10.2147/CEG.S39358.

11. Vanderpump MPJ. The epidemiology of thyroid diseases. In Braverman LE, Utiger RD, (eds).Werner and Ingbar's The Thyroid: A Fundamental and Clinical Text, 9th edn, 2005; pp 398-406. JB Lippincott-Raven: Philadelphia.

12. El Baba KA, Azar ST.Thyroid dysfunction in pregnancy. Int J Gen Med. 2012; 5:227-30. doi: 10.2147/IJGM.S27009.

13. Walker WHC. An Approach to immunoassay. Clin Chem 1977; 23(2):384-402.

14. Schuurs AHWM, Van Weemen BK. Enzyme Immunoassay. Clin. Chem. Acta 1977; 81 (5): 1-40.

15. Uotila M, Ruoslahti E and Engvall E. Two-site sandwich enzyme immunoassay with monoclonal antibodies to human alpha-fetoprotein. J Immunol Methods. 1981; 42(1): 11-15.

16. Bergmeyer HU, Hørder M, Rej R. International Federation of Clinical Chemistry (IFCC) Scientific Committee, Analytical Section: approved recommendation (1985) on IFCC methods for the measurement of catalytic concentration of enzymes. Part 3. IFCC method for alanine aminotransferase (L-alanine: 2-oxoglutarate aminotransferase, EC 2.6.1.2). J Clin Chem Clin Biochem. 1986; 24(7):481-95.

17. Oosterbann RJ, Frequency and Regression, In: Drainage Principles and Application S, H.P. Ritzema (Ed.), Chapter 6, Second Edition (Completely revised), 1994; pp 175-223. ILRI Publication, The Netherlands.

18. Taylor R. Interpretation of the correlation coefficient: A basic review. JDMS. 1990; 6(1): 35-39.

19. El-Kabbany ZA, Hamza RT, Hakim ASA, Tawfik LM. Thyroid and Hepatic Haemodynamic Alterations among Egyptian Children with Liver Cirrhosis. ISRN Gastroenterol 2012; 2012: 595734. doi: 10.5402/2012/595734.

20. Kubota S, Amino N, Matsumoto $Y$, et al. Serial changes in liver function tests in patients with thyrotoxicosis induced by Graves' disease and 
painless thyroiditis. Thyroid 2008; 18:283-287.

21. Barzilay-Yoseph L, Shabun A, Shilo L, Hadary R, Nabriski D, Kitay-Cohen Y. Thyrotoxic hepatitis. Isr Med Assoc J. 2011; 13:448-450.

22. Kandil E, Khalek MA, Thethi T, Abd Elmageed Z, Khan A, Jaffe BM. Thyroid storm in a patient with fulminant hepatic failure. Laryngoscope. 2011; 121(1):164-166.

23. Biscoveanu M, Helsinki S. Abnormal results of liver function tests in patients with Grave's disease. Endocr Pract. 2000; 6(5):367-9.

24. Khan A, Khan MMA, Ahktar S. Thyroid disorders, Etiology and Pevelance. J Med Sci 2002;2(2):
89-94.

25. Y Mane A, Bhagwat $V$. Serum enzymes and liver function tests in thyroid disorders. Biomedicine. 2011; 31(4):517-522

26. Hull K, Horenstein R, Naglieri R, Munir K, Ghany M, Celi FS. Two cases of thyroid storm-associated cholestatic jaundice. Endocr Pract 2007; 13(5):476-80.

27. Mansour-Ghanaei F, Mehrdad M, Mortazavi S, Joukar F, Khak M, Atrkar-Roushan Z. Decreased serum total T3 level in hepatitis $B$ and $C$ related cirrhosis by severity of liver damage. Ann Hepatol. 2012; 11(5): 667-71.

\begin{tabular}{l} 
AUTHOR AFFILIATION: \\
Jasmine Shah \\
Institute of Chemical Sciences \\
University of Peshawar, Pakistan. \\
Mohammad Yousaf (Corresponding Author) \\
Department of Chemistry \\
Islamia College Peshawar, Pakistan. \\
Email: yousaf672010@hotmail.com \\
Muhammad Rasul Jan \\
Institute of Chemical Sciences \\
University of Peshawar, Pakistan. \\
\hline
\end{tabular}

